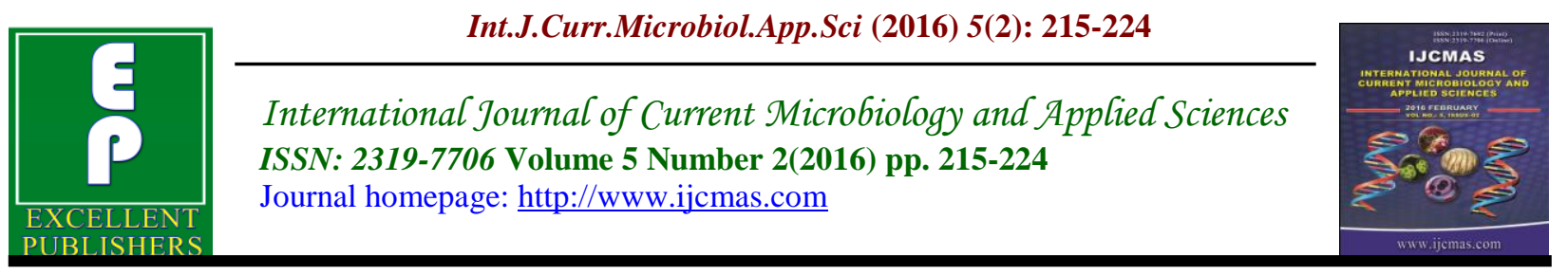

Original Research Article

doi: http://dx.doi.org/10.20546/ijcmas.2016.502.024

\title{
Isolation and Characterization of a Halophilic Cyanobacterium Euhalothece SLVH01 from Sambhar Salt Lake, India
}

\author{
Harshil H. Bhatt ${ }^{1}$, Renu Pasricha ${ }^{2}$ and Vivek N. Upasani ${ }^{3 *}$ \\ ${ }^{1}$ Department of Biotechnology, Kadi Sarva Vishwavidyalaya, Gandhinagar-382015, India \\ ${ }^{2}$ National Centre for Biological Sciences, Bangalore-560065, India \\ ${ }^{3}$ Department of Microbiology, M. G. Science Institute, Navrangpura, Ahmedabad, India
}

*Corresponding author

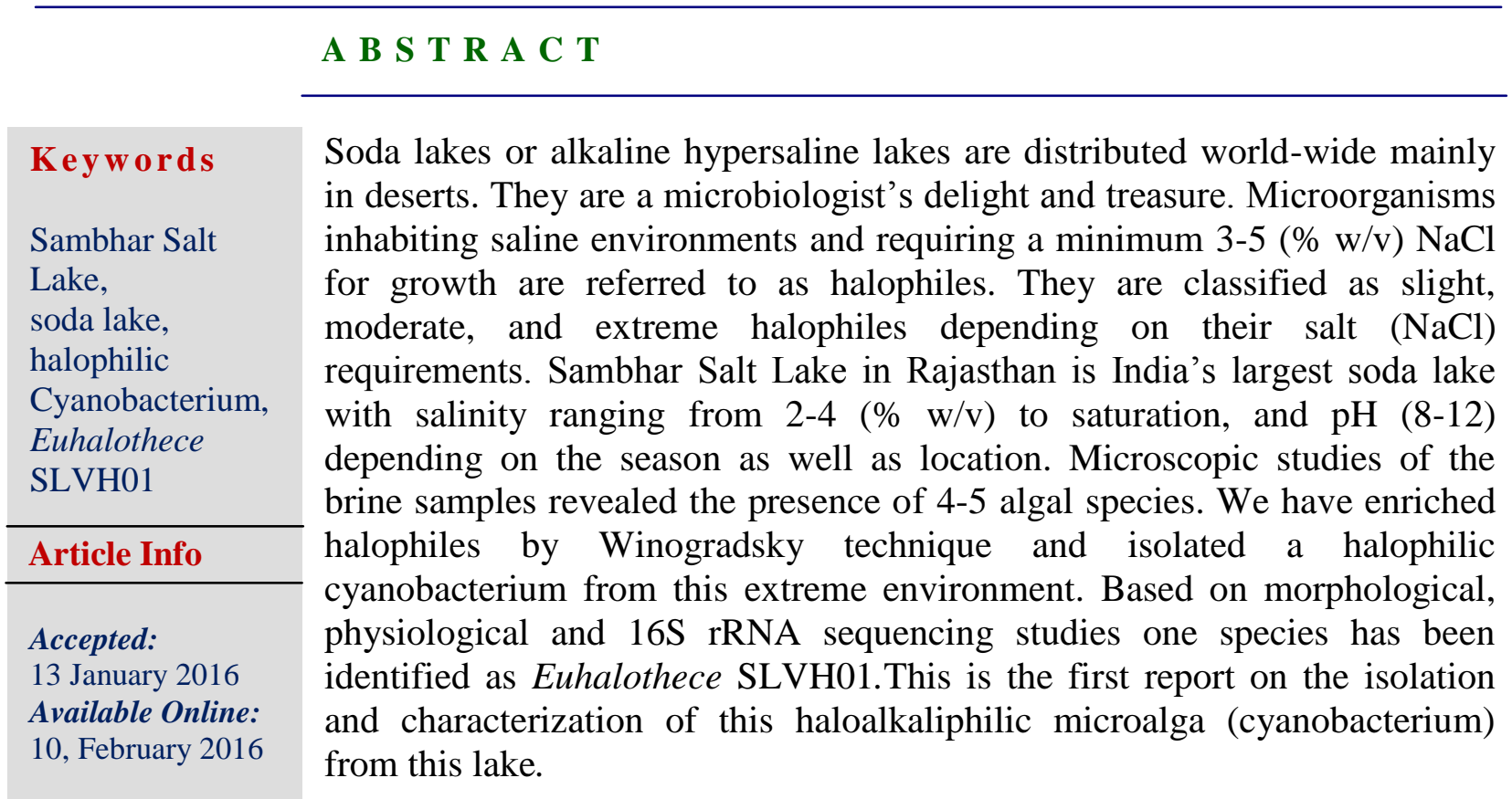

\section{Introduction}

Some of the well-known soda lakes that have been explored for microbial diversity include: The Kenyan-Tanzanian Rift Valley lakes (Lake Magadi, Lake Bogoria, Lake Natron, etc.); Owens Lake, Lake Texcoco, Albert Lake, etc., in the Americas; Chita and Bikal region, Loonar Lake, Tafusu Lake, Sambhar Salt Lake, etc., in Asia (6,17).
Sambhar Salt Lake is the largest soda lake in India with 190 sq. kms area and situated in the gaps of Aravali mountain range $(9,12)$. The water from this lake is an important source of salt $(\mathrm{NaCl})$ and other chemicals since ancient times. The chemical composition and isolation of haloalkaliphilic archaea and algae from this lake has been reported $(15,17)$. The cyanobacteria or 
prokaryotic algae belonging to the Cyanophyceae are considered to be responsible for the presence of oxygen in the atmosphere and have evolved during the Precambarian era (20). Microalgae are the primary producers in this lake and serves as food for flamingos, other birds and zooplankton. Low algal biomass and/or its quality results, decrease in the number of lesser flamingos in Kenyan Rift Valley lakes. A rise in the population of Anabaenopsis causes death of flamingos (11). Their lysis at higher salinity releases nutrients for the growth of extremely halophilic bacteria (6.17). The microbial ecology of soda lakes has been reviewed by Grant et. al. (7). Besides the cyanobacteria and eukaryotic algae, anoxygenic phototrophs and halophilic archaea are the predominant microorganisms in this environment. The isolation of Ectothiorhodhospira, Natronobacterium and Natronococcus species from the African Rift Valley lakes $(8,16)$ triggered an interest on the research related to the diversity and applications of haloalkaliphiles from desert lakes. The halophilic microalgae reported from saline and alkaline lakes include Anabaenopsis arnoldii, Chloroflexus, Chroococcus, Dunaliella salina, Spirulina sp./Arthrospira platensis, Synechococcus sp., etc. $(6,7)$. Some of these algae such as Spirulina spp. and Dunaliella salina, are used as a source of food supplement, $\beta$ carotene, glycerol, biofuel, essential omega fatty acid production, etc. Many reports are available on diversity of bacterial and archaeal species from soda lakes, but algal diversity is still a thrust area.

Hence our research was focused on studying the microalgal flora and photosynthetic bacteria of Sambhar Salt Lake by enriching these organisms by Winogradsky column. This resulted in the isolation of a cyanobacterium strain from the brines (water samples). Based on morphological, physiological and 16S rRNA sequencing the isolate was identified as Euhalothece SLVH01.

\section{Materials and Methods}

\section{Sample Collection}

Brine, soil and salt samples were collected from Devyani region, Sambhar Salt Lake, Rajasthan and were brought to the laboratory in sterile bottles $(500 \mathrm{ml})$. Samples were examined under microscope for presence of microalgae. The samples were stored at $4^{\circ} \mathrm{C}$ in a refrigerator.

\section{Isolation and Cultivation}

Winogradsky column was developed with soil and brine samples from this lake by incubating it for several months in sunlight. The enriched algal culture was inoculated into $250 \mathrm{ml}$ of BG 11 medium (Himedia, India) which consisted of $(\mathrm{g} / \mathrm{l})$ : sodium nitrate, $1.5 ; \quad$ dipotassium hydrogen phosphate, 0.0314; magnesium sulphate, 0.036; calcium chloride dehydrate, 0.0367 ; sodium carbonate, 0.020 ; disodium magnesium EDTA, 0.001; citric acid, 0.056; ferric ammonium citrate, 0.006; final $\mathrm{pH}$ was adjusted to 8.0. Incubation was carried out at $30^{\circ} \mathrm{C}, 200$ lux light with the photoperiod 16:8 (light: dark ratio). Growth was observed at 5 days interval. Serial dilution technique and combinations of different antibiotics were used to obtain pure culture.

\section{Studies on Morphology and Growth Conditions}

Photomicrographs of the isolate were taken with a Leica bright field microscope DM2500 with camera attachment (45X magnification). The effect of $\mathrm{NaCl}$ (\%w/v) 5.0, 10.0 and $15.0 \mathrm{~g} / 100 \mathrm{ml}$; $\mathrm{pH}: 8.0$, 9.0 and 10.0 ; and temperatures $25^{\circ} \mathrm{C}, 30^{\circ} \mathrm{C}$ 
and $40^{\circ} \mathrm{C}$ were studied to optimize growth conditions. Culture was incubated as described earlier for 14 days, cells were harvested by centrifugation at $6000 \mathrm{rpm}$ and total wet biomass was calculated. Pigments were extracted from the cyanobacterial biomass in the solvents acetone and methanol for chlorophyll analysis. Spectra were taken using UV-Vis spectrophotometer Shimadzu 700.

\section{FAME Analysis}

Fatty Acid Methyl Esters (FAME) was prepared by direct trans-esterification method (1). Sample was treated with $1.0 \mathrm{ml}$ toluene and $5 \% \mathrm{HCl}$ in methanol and then homogenized and vortexed at low speed. Sample was kept at $70^{\circ} \mathrm{C}$ for 2 hours in a water bath. The solution was allowed to cool at room temperature and neutralized with $6 \% \mathrm{~K}_{2} \mathrm{CO}_{3}$. FAMEs were extracted with hexane, centrifuged and the supernatant was preserved (hexane extract) at $4-10^{\circ} \mathrm{C}$. GC analysis was carried out at SICART, Vallabh Vidhyanagar, Gujarat (GC: Perkin Elmer Auto system XL with FID detector).

\section{Transmission Electron Microscopy (TEM)}

TEM was carried out at Microscopy Lab., NCBS, Bangalore. Cells collected by centrifugation were first fixed overnight with the primary fixative glutaraldehyde (2.5\%, containing $3.0 \mathrm{~g} \% \mathrm{NaCl})$. Post fixation was done with $1.0 \mathrm{~g} \%$ of Osmium tetroxide. Staining was carried out with $2 \mathrm{~g} \%$ Uranyl acetate and washing with Milli Q water, respectively. The samples were dehydrated in graded ethanol series. Samples were embedded in resin 812 and polymerized at $70^{\circ} \mathrm{C}$ for $1-2$ days. Images were captured on Tecnai G2 Spirit BioTWIN electron microscope.

Table.1 The 16S rRNA sequences from GenBank (NCBI) and their accession numbers.

\begin{tabular}{|llc|}
\hline Sr. No. & Organisms & Gene Bank Accession number \\
\hline $\mathbf{1}$ & Euhalothece sp. SLVH01 & KC924847.1 \\
\hline $\mathbf{2}$ & Euhalothece sp. MPI 95AH10 & AJ000709.1 \\
\hline $\mathbf{3}$ & Euhalothece sp. MPI 95AH13 & AJ000710.1 \\
\hline $\mathbf{4}$ & Euhalothece sp. Z-M001 & EU628548.1 \\
\hline $\mathbf{5}$ & Euhalothece sp. BDU 130911 & KM350247.1 \\
\hline $\mathbf{6}$ & Euhalothece sp. BDU 130192 & KF498709.1 \\
\hline $\mathbf{7}$ & Euhalothece sp. BDU 130913 & KM350246.1 \\
\hline $\mathbf{8}$ & Euhalothece sp. MPI 96N304 & AJ000713.1 \\
\hline $\mathbf{9}$ & Euhalothece sp. MPI 96N303 & AJ000712.1 \\
\hline $\mathbf{1 0}$ & Cyanothece sp. PCC 7418 & AJ000708.1 \\
\hline $\mathbf{1 1}$ & Halothece sp. PCC 7418 & NR_102451.1 \\
\hline $\mathbf{1 2}$ & Halothece sp. PCC 7418 (1) & AF296872.1 \\
\hline $\mathbf{1 3}$ & Aphanothece naegelii KCTC AG10042 & AY121354.1 \\
\hline $\mathbf{1 4}$ & Aphanothece naegelii KCTC AG10041 & AY121353.1 \\
\hline $\mathbf{1 5}$ & Xenococcaceae cyanobacterium CENA331 & KT731151.1 \\
\hline $\mathbf{1 6}$ & Cyanobacterium GI-1 & JN202625.2 \\
\hline $\mathbf{1 7}$ & Chroococcidiopsis sp. CCMP1991 & JF810072.1 \\
\hline $\mathbf{1 8}$ & Synechococcus sp. HOG & AF448075.1 \\
\hline $\mathbf{1 9}$ & Gloeothece sp. KO68DGA & AB067580.1 \\
\hline $\mathbf{2 0}$ & Uncultured cyanobacterium clone WP3 & JN122739.1 \\
\hline $\mathbf{2 1}$ & Uncultured cyanobacterium clone LL31B & EF106405.1 \\
\hline
\end{tabular}




\section{S rRNA Sequencing and Phylogenetic} Tree

The genomic DNA was isolated from the algal culture and PCR amplification was carried out using cyanobacterial 16S rRNA primers CYA359F (GGGGAATYTTCC GCAAT- GGG) and CYA781R (GACTAC TGGGGTATCTAATCCCATT) as described by Nubel Garcia-Pichel and Muyzer (14). PCR product was sequenced using ABI 3130 automated sequencer (Applied Biosystems) at Chromous Biotech Pvt. Ltd., Bangalore.

In all twenty one (21) 16S rRNA sequences (including our isolate) from GenBank, NCBI for Euhalothece and related genera/strains were used for phylogenetic analysis (Table 1). Neighbour-joining (N-J) method was used to construct the phylogenetic tree using Molecular Evolutionary Genetics Analysis (MEGA6) software.

\section{Results and Discussion}

\section{Sampling and Enrichment}

Samples were collected from Devyani kyars (pans), Sambhar Salt Lake, Rajasthan (Fig. 1). Although soda lakes provide extreme growth conditions, our results show that it is rich in microbial diversity, especially that of haloalkaliphilic microalgae at low to moderate salt concentration. The colour of the brines/water in the kyars changed with season as it brings about physicochemical changes that allow succession of diverse microbial species.

Diversity of microalgae was examined microscopically from natural samples and the enrichment culture obtained by Winogradsky's column. The samples contained mainly oval, coccoid, spiral, filamentous and rod-shaped microalgae. An alga in tetrad form was also observed. Various shapes of bacteria were also abundant.

Fig. 1. Sample collection sites, Devyani Kyars, Sambhar Lake, India

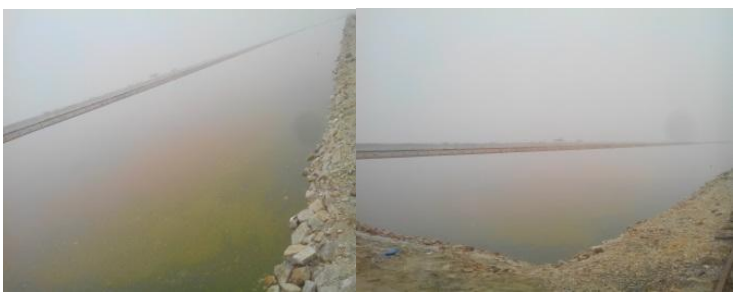

Studies on Cultivation, Morphology and Growth

The enriched culture in BG 11 was observed after incubation at $30^{\circ} \mathrm{C}$ for 14 days. The contamination by bacteria especially actinomycetes was inhibited by the addition of three antibiotics (Nalidix acid 10mg/l, Trimethoprim $20 \mathrm{mg} / \mathrm{l}$ and Cycloheximide $20 \mathrm{mg} / \mathrm{l})$. Pure culture of an oval to rodshaped cyanobacterium was obtained by serial dilution and designated as strain SLVH01 (Fig. 3).

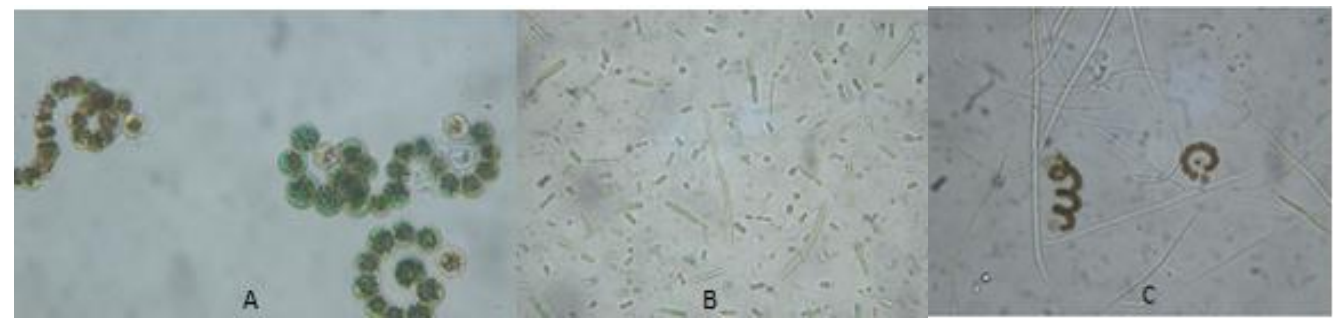

Fig. 2. Photomicrographs of microalgal species observed in the enriched culture by Winogradsky column. A. Spiral species (Anabaenopsis sp.) with heterocysts; B. Filamentous, coccoid and rod shaped; C. Filamentous and spiral forms. 


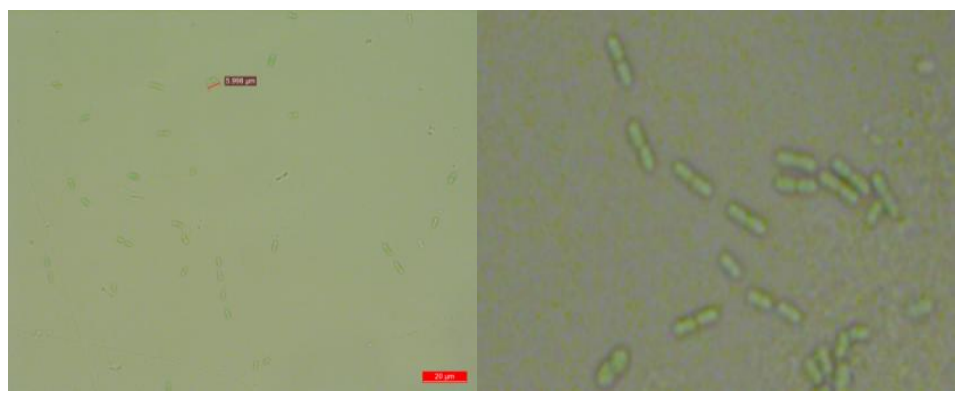

Fig. 3. Photomicrograph of Euhalothece sp.SLVH01

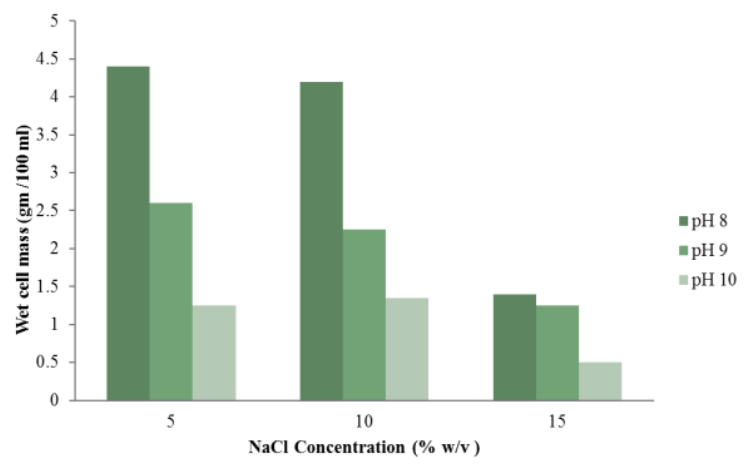

Fig. 4. Growth of Euhalothece SLVHO1 at different salt and pH.

Table.2 Qualitative FAMEs analysis by GC of hexane extract of SLVH01 strain.

\begin{tabular}{|lll|}
\hline Sr.No. & Fatty Acid & \% content \\
\hline 1 & Lauric Acid (12:0) & 4.68 \\
\hline 2 & Myristic Acid (14:0) & 2.97 \\
\hline 3 & Palmitic Acid (16:0) & 8.53 \\
\hline 4 & Palmitoleic Acid (16:1) & - \\
\hline 5 & Stearic Acid (18:0) & - \\
\hline 6 & Oleic Acid (18:1) & 6.63 \\
\hline 7 & Linoleic Acid (18:2) & 3.67 \\
\hline 8 & Linolenic Acid (18:3) & - \\
\hline 9 & Arachidic Acid (20:0) & 5.32 \\
\hline 10 & Erucic Acid (22:1) & 8.02 \\
\hline 11 & Unknown fatty acids & 60.18 \\
\hline
\end{tabular}

The microalgal strain grew optimally at $5 \% \mathrm{w} / \mathrm{v}, \mathrm{NaCl}$ and $\mathrm{pH} 8.0$ at temperature $30^{\circ} \mathrm{C}$ (Fig. 4). The strain grew well upto $10 \% \mathrm{w} / \mathrm{v} \mathrm{NaCl}$ and $\mathrm{pH} 8.0$, however further increase in $\mathrm{NaCl}$ and $\mathrm{pH}$ had adverse effect on its growth. No growth was obtained in absence of $\mathrm{NaCl}$ and $\mathrm{pH}$ 7.0.

\section{FAME Analysis}

This is the first report on the fatty acid composition of a Euhalothece strain. Table 2 indicates higher content of saturated fatty acids as compared to unsaturated fatty acids. The major fatty acids present were palmitic 
acid, oleic acid and erucic acid. However, it was surprising to note that in this preliminary study about $60 \%$ of the fatty acids were unknown. It contains the essential fatty acid linoleic acid (Omega 6 fatty acid) amount (3.63\%).

\section{TEM Studies}

The cells of SLVH01 were prokaryotic, oval or rod-shaped (2.0 to 5.0-6.0 $\mu \mathrm{m})$. There is a single outer membrane structure and cellwall was not observed. It shows lengthwise pattern of thylakoids in fascicles. The development of a daughter cell attached with parental cell was observed. Intracellular carboxysome granules and osmiophylic eyespot globules were present (Fig. 5). Osmiophylic eyespot globules have been reported in the apical cells of Leptolyngbya spp. (2).

\section{Phylogenetic Analysis}

The 16S rRNA was amplified and sequencing data of the $770 \mathrm{bp}$ product was analyzed by BLAST tool and the strain was identified and designated as Euhalothece
SLVH01. Sequence was submitted to Gene Bank, accession number: KC924847.1. The phylogenetic tree revealed that Euhalothece SLVH01 was closely related with four strains mentioned in cluster one, as shown in Fig. 6.

Samples were collected from shallow solar salt pans, where salinity was $5-10 \%$, as at higher salt concentrations the microalgae lysed, providing nutrients for the growth of halophilic bacterial strains $(12,18)$. We were successful in enrichment of phototrophs by Winogradsky Column (Fig. 2). After 6-8 months there was an increase in the algal community mainly cyanobacteria as also reported by Mikhodyuk et. al. (13). The column turned from red-pink to green on prolonged incubation, showing the succession of cyanobacteria. This inspired us for the isolation and identification of haloalkaliphilic microalga from the enrichment culture. Isolation of Euhalothece species has been reported from Lake Magadi and Eilat, Israel $(10,13)$.

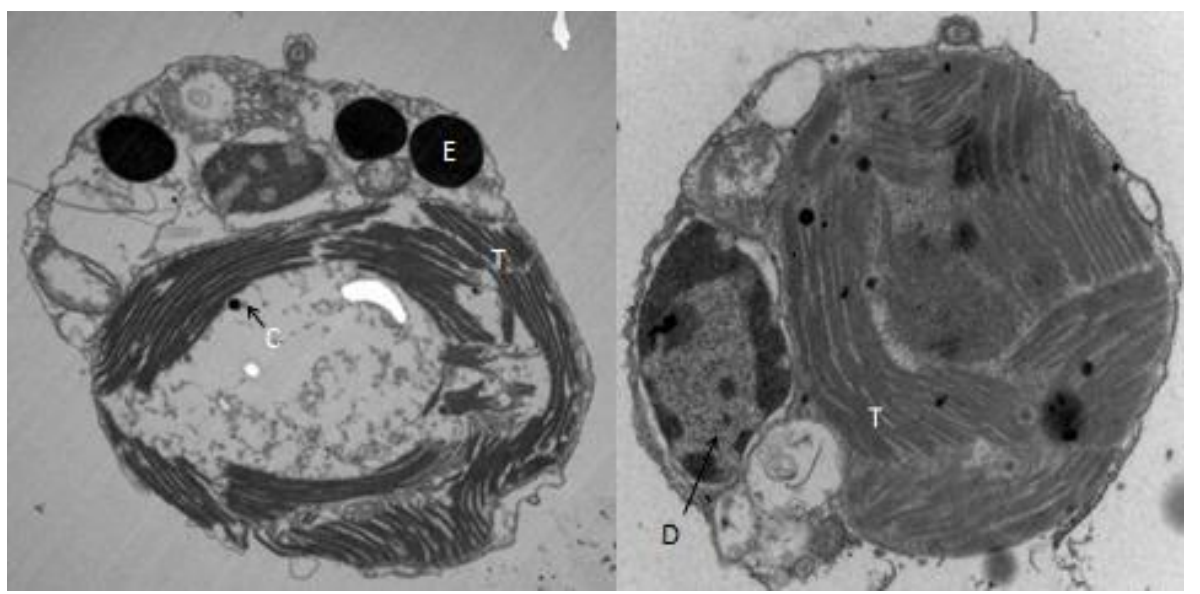

Fig.5 TEM image of SLVH01 strain (Longitudinal section). T: thylakoids pattern, D: daughter cell, C: carboxysome, E: eyespot globules 


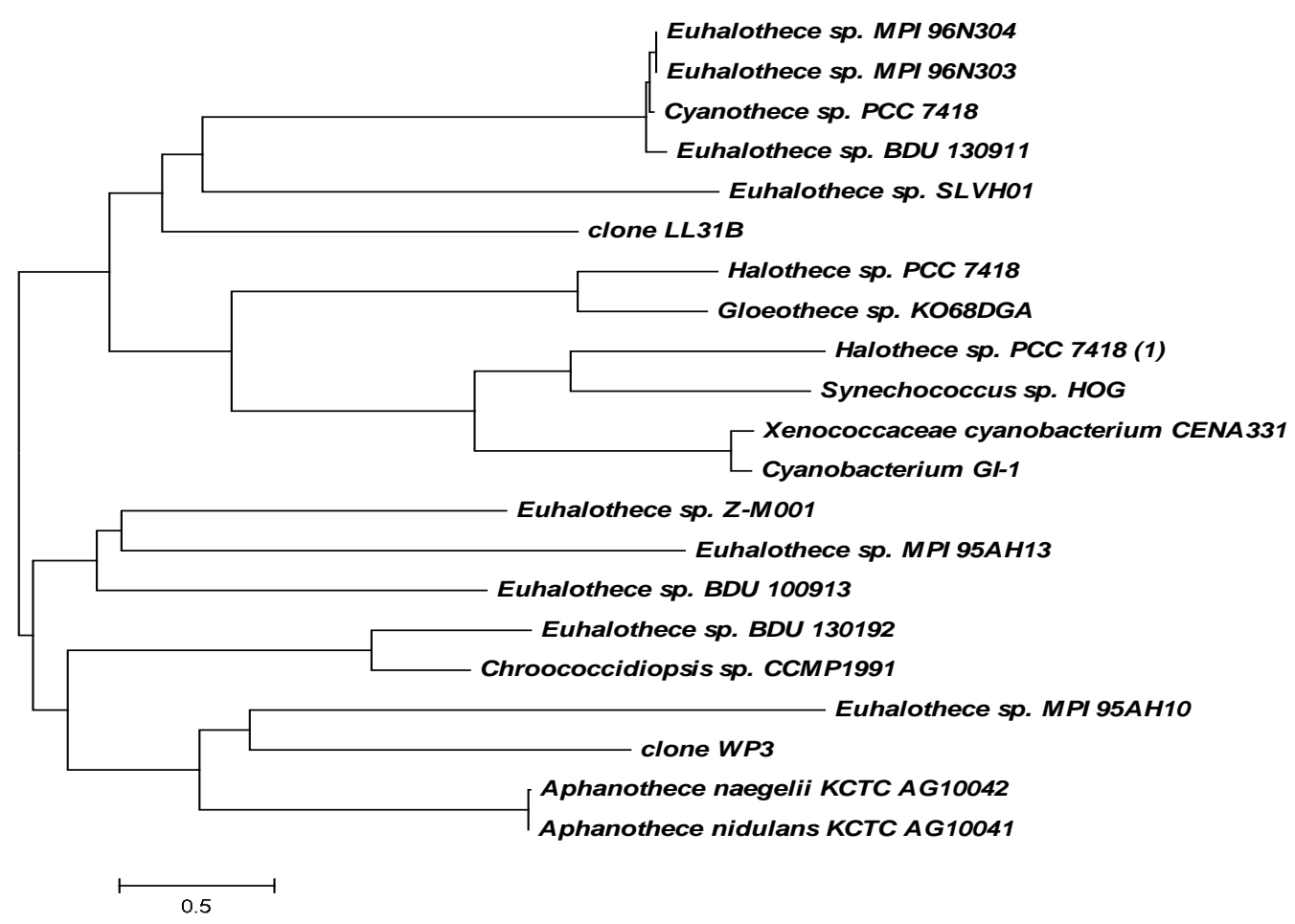

Fig. 6. Phylogenetic tree showing position of SLVH01 strain

Garcia-Pichel et al. (4) reported that the morphology of the unicellular cyanobacteria belonging to "Euhalothece" and "Halothece" was diverse and dependent on the culture conditions. Cell widths varied from 2.8 to $10.3 \mu \mathrm{m}$. The cells of SLVH01 strain were oval to rod-shaped, dividing, singly or pairs, size 2.0 to $5.0-6.0 \mu \mathrm{m}$. The cyanobacterium SLVH01 strain was moderately halophilic and alkaliphilic and grew optimally in BG 11 medium, as compared to other media used for algal cultivation. The growth of this strain in liquid medium was turbid, uniform, dark green after 10-15 days of incubation, and did not form sediment or clumps. In our attempts to isolate on solid media, no growth was observed by streaking, but the strain formed colonies within the medium in case of pour plate method. UV-Vis spectroscopy revealed the presence of Chlorophyll $a$ and $b$ in the strain, in the methanol and acetone extracts.
Our preliminary qualitative data of FAMEs analysis of SLVH01 strain, showed the presence of $60 \%$ unknown fatty acids content (as only 10 fatty acid standards were used), and therefore further studies need to be carried out to know the exact lipid profile. Omega 6-linoleic acid content was less.

Most of the cyanobacteria produce mucilages sheath, which accumulate around the cells or trichome to form an envelope or sheath that allows the cells to aggregate and form colonies. This feature was absent in the TEM images SLVH01 strain. The cyanobacteria belonging to the Euhalothece group 1 possess parallel, lengthwise arranged thylakoids through the whole cell volume with distinct or indistinct fascicles (3).

The phylogenetic analysis with 20 related cultures resulted in their grouping into four (4) clusters as follows: (I) Euhalothece sp. 
MPI 96N304, Euhalothece sp. MPI 96N303, Euhalothece sp. BDU 130911, Euhalothece sp.SLVH01 and Cyanothece sp. PCC 7418; (II) Halothece sp. PCC 7418 and Gloeothece sp. KO68DGA; Halothece sp. PCC 7418 (1), Synechococcus sp. HOG, Xenococcaceae cyanobacterium CENA 331 and Cyanobcterium GI-1; (III) Euhalothece sp. Z-M001, Euhalothece sp. MPI 95AH13 and Euhalothece sp. BDU 100913; (IV) Euhalothece sp. BDU 130192, Chroococcidiopsis sp. CCMP1991, Euhalothece sp. MPI95AH10, Clone WP3, Alphanothece naegelii KCTC AG10042 and Alphanothece nidulans KCTC AG10041. Clone LLB31 and Euhalothece sp. BDU 100913 appeared as individual entity in cluster one and cluster three respectively. In the Bergey's Manual of Systematic Bacteriology (vol. 1, 2001), the phylogenetic trees included on the basis of cyanobacterial 16S rRNA sequences have a "fan-like" appearance that shows the evolution of oxygenic photosynthesis during a brief period. Based on the distance trees constructed by Neighbour-joining method and Maximum Likelihood method the cyanobacteria have been classified into fourteen (14) clusters (21). Accordingly, the strains belonging to the genus Euhalothece belong to the Cluster VII. The halotolerant unicellular strains. They are moderately thermophilic and mainly found in marine and euryhaline habitats. The cyanobacterium isolate SLVH01 belongs to the Form-genus V. Cyanothece, Cluster 3, as it grows best at $\mathrm{NaCl}$ concentration greater than $5.0 \% \mathrm{w} / \mathrm{v}$ (slight growth at $15 \% \mathrm{w} / \mathrm{v}$ ), however it differs from the two strains PCC 7418 and PCC 9711 isolated from solar evaporation ponds $(4,5)$ as they are moderately alkaliphilic growing well at $\mathrm{pH}$ between 810.0. A haloalkaliphilic Euhalothece strain Z-M001, has been isolated from the saline and alkaline water samples from Lake Magadii (13). However, our strain SLVH01 and Z-M001 belong to different clusters (Fig. 6).

Mycosporin- like amino acids (MAAs) has been reported mainly in macro and microorganisms of marine environments. MAAs absorbs UV light and thus it protects the cell from UV radiation. Mycosporine-2Glycine and 2-(E)-3-(E)-2,3-dihydroxyprop1-enylimino-mycosporine-alanine has been reported from Euhalothece sp. isolated from hypersaline saltern pond in Eilat, Israel $(10,19)$. MAA was not detected in our isolate (unpublished results).

This is the first report of isolation and characterization of a haloalakliphilic cyanobacterium belonging to the genus Euhalothece from the saline waters of Sambhar Lake, India.

\section{Acknowledgement}

We are grateful to the M. G. Science Institute and Ahmedabad Education Society for providing lab facilities. We acknowledge the support of DBT grants under Star College Scheme; for TEM at C-CAMP; and Institute of Life Sciences (Ahmedabad University) for photomicrography.

\section{References}

1. Alves, S. P., Carbita, A. R. J., Fonseca, A. J. M. \& Bessa, R. J. B. 2008. Improved method for analysis in herbage based on direct transesterification followed by solidphase extraction. J. Chrom. 1209:212219.

2. Barsanti, L. \& Gualtieri, P. 2014. Algae: Anatomy, Biochemistry and Biotechnology, 2nd ed. CRC press, FL, USA, $51 \mathrm{pp}$.

3. Cepak, V. \& Komarek, J. 2010. Cytomorphology of six halotolerant 
coccoid cyanobacteria using DAPI fluorescent and transmission electron microscopy, compared with molecular data. Fottea 10(2):229-234.

4. Garcia-Pichel, F., Nubel, U. \& Muyzer, G. 1998. The phylogeny of unicellular, extremely halotolerant cyanobacteria. Arch. Microbial. 169:469-482.

5. Garlick, S., Oren, A. \& Pedan, E. 1977. Occurrence of facultative anoxygenic photosynthesis among filamentous and unicellular cyanobacteria. J. Bacteriol. 129:623-629.

6. Grant, W. D. \& Tindall, B. J. 1986. The Alkaline saline environments. In Herbert, R. A. \& Codd, G. A. (eds.) Microbes in extreme environments. Academic Press, London, pp. 25-54.

7. Grant, W., Jones, B., Duckworth, A. \& Owenson, G. 1998. Microbial diversity of soda lakes. Extremophiles 2:191200.

8. Imhoff, J. F. \& Trüper, H. G. 1977. Ectothiorhodospira halochloris sp. nov., a new extremely halophilic phototrophic bacterium containing bacteriochlorophyll b. Arch. Microbiol. 130:238-242.

9. Jakher, G., Bhargava, S. \& Sinha, R. 1990. Comparative limnology of Sambhar and Didwana lakes (Rajasthan, NW India) Hydrobiologia 197 (1):245-256.

10. Kedar, L., Kashman, Y. \& Oren, A. 2002. Mycosporine-2-glycine is the major mycosporine-like amino acid in a unicellular cyanobacterium (Euhalothece sp.) isolated from a gypsum crust in a hypersaline saltern pond. FEMS Microbiol. Letters 208:233-237.

11. Krienitz, L. \& Kotut, K. 2010. Fluctuating Algal food populations and the occurrence of lesser flamingos (Phoeniconaias minor) in three Kenyan
Rift Valley Lakes. J. Phycol. 46:10881096.

12. Kumar, S. 2008. Conservation of Sambhar Lake- An important waterfowl habitat and a Ramsar Site in India. Proceedings of TAAL2007-The 12th World Lake Conference. 15091517.

13. Mikhodyuk, O. S., Gerasimenko, L. M., Akimov, V. N., Ivanovsky R. N., \& Zavarzin, G. A., 2008. Ecophysiology and polymorphism of the unicellular extremely natronophilic cyanobacterium Euhalothece sp. ZM001 from Lake Magadi. Microbiol. 77:717-725.

14. Nubel, U., Garcia-Pichel, F. \& Muyzer, G. 1997. PCR Primers to amplify $16 \mathrm{~S}$ rRNA genes from cyanobacteria. Appl. envi. microbial. 63:3327-3332.

15. Sharma, P., Agarwal, V., Mohan, M. K., Kachhwaha, S., Kothari S. L. 2012. Isolation and Characterization of Dunaliella Species from Sambhar Lake (India) and its Phylogenetic Position in the Genus Dunaliella Using 18S rDNA, Natl. Acad. Sci. Lett. 35:207-213.

16. Tindall, B. J., Ross, H. N. M. \& Grant, W. D. 1984. Natronobacerium, gen. nov. and Natronococcus, gen. nov., two new genera of haloalkaliphilic archeobacteria. Syst. Appl. Microbiol. 5:41-57.

17. Upasani, V. \& Desai, S. 1990. Sambhar Salt Lake: chemical composition of brines and studies on haloalkaliphilic archeobacteria. Arch. Microbiol. 154:589-593.

18. Upasani, V. N. 2008. Microbiological studies on Sambhar Lake (Salt of Earth) Rajasthan, India. In Proceedings of TAAL2007-The $12^{\text {th }}$ World Lake Conference. 448-450.

19. Volkmann, M., Gorbushina, A., Kedar, L. \& Oren, A. 2006. Structure of euhalothece-362, a novel red-shifted 
mycosporine-like amino acid, from a halophilic cyanobacterium (Euhalothece sp.). FEMS Microbiol Letters 258:50-54.

20. Wilmotte, A., Turner, S., Peer, Y. Van de, \& Pace, N. R. 1992. Taxonomic study of marine oscillatoriacean strains (Cyanobacteria) with narrow trichomes: II. Nucleotide sequence analysis of the $16 \mathrm{~S}$ ribosomal RNA. J. Phycol. 28: 828-838.
21. Wilmotte, A. \& Herman, M. 2001. Phylogenetic relationships among the cyanobacteria based on 16S rRNA sequences. In Boone, D. R. \& Castenholz, (eds.) Bergey's Manual of Systematic Bacteriology. 2nd ed., vol. I Springer, New York, 487-493 pp.

\section{How to cite this article:}

Harshil H. Bhatt, Renu Pasricha and Vivek N. Upasani. 2016. Isolation and Characterization of a Halophilic Cyanobacterium Euhalothece SLVH01 from Sambhar Salt Lake, India. Int.J.Curr.Microbiol.App.Sci.5(2): 215-224. doi: http://dx.doi.org/10.20546/ijcmas.2016.502.024 